\title{
Aggression, Suicidality, and Intermittent Explosive Disorder: Serotonergic Correlates in Personality Disorder and Healthy Control Subjects
}

\author{
Emil F Coccaro*,', Royce Lee' and Richard J Kavoussi' \\ 'Clinical Neuroscience and Psychopharmacology Research Unit, Department of Psychiatry and Behavioral Neuroscience, Pritzker School of \\ Medicine, University of Chicago, Chicago, IL, USA
}

\begin{abstract}
Central serotonergic (5-HT) activity has long been implicated in the regulation of impulsive aggressive behavior. This study was performed to use a highly selective agent for 5-HT (d-Fenfluramine, d-FEN) in a large group of human subjects to further explore this relationship dimensionally and categorically. One hundred and fifty healthy subjects ( 100 with personality disorder, PD and 50 healthy volunteer controls, HV) underwent d-FEN challenge studies. Residual peak delta prolactin ( $\triangle \mathrm{PRL}[\mathrm{d}-\mathrm{FEN}]-\mathrm{R}$; ie, after the removal of potentially confounding variables) was used as the primary 5-HT response variable. Composite measures of aggression and impulsivity were used as dimensional measures, and history of suicidal/self-injurious behavior as well as the presence of intermittent explosive disorder (IED) were used as categorical variables. $\triangle \mathrm{PRL}[\mathrm{d}-\mathrm{FEN}]-\mathrm{R}$ responses correlated inversely with composite aggression, but not composite impulsivity, in all subjects and in males and females examined separately. The correlation with composite aggression was strongest in male PD subjects. $\triangle \mathrm{PRL}[\mathrm{d}-\mathrm{FEN}]-\mathrm{R}$ values were reduced in PD subjects with a history of suicidal behavior but not, selfinjurious behavior. $\triangle \mathrm{PRL}[\mathrm{d}-\mathrm{FEN}]-\mathrm{R}$ values were also reduced in patients meeting Research Criteria for IED. Physiologic responses to 5-HT stimulation are reduced as a function of aggression (but not generalized impulsivity) in human subjects. The same is true for personality disordered subjects with a history of suicidal, but not self-injurious, behavior and for subjects with a diagnosis of IED by research criteria. These data have particular relevance to the notion of impulsive aggression and the biological validity of IED. Neuropsychopharmacology (2010) 35, 435-444; doi:I 0.1038/npp.2009. I48; published online 23 September 2009
\end{abstract}

Keywords: 5-HT; d-Fenfluramine; aggression; impulsivity; suicidality; IED

\section{INTRODUCTION}

The hypothesis that serotonin (5-HT) modulates impulsive aggressive behavior in humans has been in the literature since the late 1970s (Asberg et al, 1976; Brown et al, 1979; Sheard et al, 1976). Data from studies of cerebrospinal fluid 5-hydroxy-indolacetic acid (CSF 5-HIAA), the major, stable metabolite of neuronal 5-HT (in alcoholic males (Limson et al, 1991), behaviorally disruptive male children and adolescents (Kruesi et al, 1990), rhesus monkeys (Higley et al, 1992) and pigtailed macaques (Westergaard et al, 1999)), frequently, though not always, demonstrate inverse correlations between CSF 5-HIAA and measures of aggression and suicidal behavior. Reduction of CSF 5-HIAA concentrations in impulsive violent offenders (Linnoila

*Correspondence: Dr EF Coccaro, Clinical Neuroscience and Psychopharmacology Research Unit, Department of Psychiatry and Behavioral Neuroscience, MC 3077; Room B330, University of Chicago, 584I South Maryland Avenue, Chicago, IL 60637, USA, Tel: 773 834-4083, Fax: 773834 7427, E-mail: ecoccaro@yoda.bsd. uchicago.edu

Received I June 2009; revised 2 I July 2009; accepted II August 2009 et al, 1983), and impulsive arsonists (Virkkunen et al, 1987) suggests that the relationship is specific to impulsivity. However, closer analysis of the impulsive arsonist group reveals that this group is quite aggressive as well (eg, similar rates of intermittent explosive disorder (IED) and history of suicide attempts (Coccaro and Siever, 2002). Accordingly, it may be more parsimonious to posit that the relationship between 5-HT and aggression and impulsivity is actually a relationship with impulsive aggression rather than a relationship with either behavioral trait alone. Lack of an inverse relationship between CSF 5-HIAA concentrations and aggression has been reported in personality disordered subjects (eg, Coccaro et al, 1997a, b). It is of note, however, that inverse correlations between hormonal responses to 5-HT pharmaco-challenge and aggression were noted in two separate studies when no such relationship was seen with CSF 5-HIAA concentrations (Coccaro et al, 1997a,b). Differences in these results are likely because of differences in the severity of aggression in the subjects (ie, very aggressive $v s$ moderately aggressive) and the nature of the subjects (ie, drawn from forensic populations vs community/clinical populations). Furthermore, these 
differences suggest that physiologic responses to 5-HT pharmaco-challenge may be more sensitive to detecting a relationship between central 5-HT and aggression than CSF 5-HIAA concentrations.

Studies of 5-HT pharmaco-challenge also demonstrate inverse correlations between the 5-HT-mediated outcome measure and aggression and/or impulsivity in most cases (Coccaro and Siever, 2002). We have reported inverse correlations between irritability and assault on the BussDurkee Hostility Inventory (BDHI) and the PRL response to $\mathrm{d}, \mathrm{l}-$ Fenfluramine challenge (PRL[d,l-FEN]) in a small group of personality disordered males (Coccaro et al, 1989). This study also noted a reduction in PRL[d,l-FEN] responses in the subjects with a history of a suicide attempt, with life history of alcoholism, and with Borderline Personality Disorder (BPD). Further analysis noted that the core relationship between PRL[d,l-FEN] and BDHI irritability/ assault accounted for all the differences between subjects who had and did not have a history of a suicide attempt, or alcoholism, or BPD. Support for these findings has been reported in many, although not all (Fishbein et al, 1989; Stoff et al, 1992; Halperin et al, 1994; Pine et al, 1997), studies including those of personality disordered subjects (New et al, 1997, 2004), suicidal subjects (Lopez-Ibor et al, 1990), violent offenders (O'Keane et al, 1992), HVs from the community (Manuck et al, 1998), and in macaques (Botchin et al, 1993).

In this study, we report on a large series of personality disordered $(n=100)$ and healthy control $(n=50)$ subjects who underwent a d-Fenfluramine (d-FEN) challenge. This study differs from our earlier study in several ways. First, there are five times as many patient subjects (100 vs 20). Second, the subjects were recruited from the local community rather than from a Veterans Hospital. Third, the sample includes females. Fourth, subjects were comprehensively assessed in terms of aggression and impulsivity and were also assessed for IED. Fifth, this study utilized d-FEN rather than d,l-FEN. Although PRL responses to d,l-FEN are very similar to those with d-FEN, the l-isomer in d,l-FEN has antagonistic effects on the dopaminergic system (Crunelli et al, 1980; Garattini et al, 1988) that can affect PRL release in response to neurotransmitter-mediated stimulation (Ben-Jonathan et al, 1989; Coccaro and Kavoussi, 1994).

On the basis of previous data in the area, we tested four hypotheses. First, prolactin responses to d-FEN will correlate inversely with aggression (and with impulsivity) scores in all subjects, all male subjects, and all PD subjects. Second, prolactin responses to d-FEN would not correlate with general measures of personality. Third, prolactin responses to d-FEN will be lower among PD subjects with a history of self-directed aggression (ie, suicide attempts) compared with PD subjects without this history and compared with HC subjects. Differences in prolactin responses to d-FEN between PD and HC subjects, and between subjects with and without a history of suicide attempt, if found, would be accounted for by differences in aggression (and/or impulsivity). Fourth, prolactin responses to d-FEN will demonstrate the greatest difference among PD subjects meeting, or not meeting, integrated research criteria for IED compared with DSM-IV criteria or with other research criteria for the diagnosis of IED.

\section{MATERIALS AND METHODS}

\section{Subjects}

One hundred subjects with personality disorder (PD) and 50 healthy control volunteer (HV) subjects participated in the study. All subjects were medically healthy. PD subjects were recruited by newspaper and public service announcements seeking subjects with, and without, self-reported problems of PD. HV subjects were recruited in the same manner but with public service announcements seeking out subjects willing to participate in biological studies of personality traits. All subjects signed the informed consent document approved by the Committee for the Protection of Human Subjects (IRB) before engaging in any study procedures. Medical health of all subjects was documented by medical history, physical examination, electrocardiogram, and blood hematology, chemistry, thyroid function tests, pregnancy test, and urinalysis, including a urine screen for drugs of abuse.

\section{Diagnostic Assessment}

Axis I and Axis II diagnoses were made according to DSM-IV criteria (American Psychiatric Association, 1994). Diagnosis of alcoholism was made by modified research diagnostic criteria as previously described(Coccaro et al, 1989, 1996a-d). Diagnosis of IED were made by DSM-IV (1994), by research criteria (IED-R; Coccaro et al, 1998a) and by the most recently described version of research criteria for IED (IED-IR: integrated for research; Coccaro, 2003). IED-R Criteria (Coccaro et al, 1998a) differ from DSM-IV criteria in that they require (a) 1-month (or more) period of aggressive outbursts (including verbal outbursts only, or outbursts in which property is not destroyed) occurring twice a week on average, (b) aggressive outbursts to be primarily impulsive in nature, (c) aggressive outbursts to be associated with significant subjective distress or psychosocial impairment, and that they allow for comorbid diagnoses of Borderline and/or Antisocial Personality Disorder. IED-IR criteria are the same except that they allow for an IED diagnosis if there are at least three episodes of serious assaultive or destructive behavior (even when there are not recurrent aggressive outbursts within the 1-month time frame as required by the initially proposed Research Criteria). The IED-IR criteria, thus, 'integrates' the originally proposed RESEARCH criteria with current DSM-IV criteria. The inter-rater reliability for the diagnosis of IED by DSM-IV, IED-R, or by IED-IR criteria was very $\operatorname{good}(\kappa>0.85)$.

Diagnoses were made using information from the following: (a) semi-structured interviews conducted by trained masters, or doctoral, level clinicians; (b) clinical interview by a research psychiatrist; and, (c) review of all other available clinical data as previously described (Bunce et al, 2005). Final diagnoses were assigned by team bestestimate consensus procedures as previously described (Bunce et al, 2005).

By definition, the $50 \mathrm{HV}$ subjects were free of current or lifetime history of Axis I or II disorder. The $100 \mathrm{PD}$ subjects were without a life history of mania/hypomania, schizophrenia, or delusional disorder or current alcohol or drug use disorders; other Axis I disorders were not exclusionary. 
Sixty-four of the PD subjects met DSM-IV criteria for specific PD as follows: (a) Cluster A $(n=18)$, ie, Paranoid $(n=13)$, Schizoid $(n=5)$, Schizotypal $(n=5)$; (b) Cluster B $(n=41)$, ie, Borderline $(n=28)$, Antisocial $(n=16)$; Narcissistic $(n=12)$; Histrionic $(n=4)$; (c) Cluster C $(n=24)$, ie, Obsessive-Compulsive $(n=18)$, Avoidant $(n=4)$; Dependent $(n=2)$. The remaining 36 subjects were diagnosed as Personality Disorder-Not Otherwise Specified. These subjects met DSM-IV general criteria for PD, had pathological personality traits from a variety of $P D$ categories, and had evidence of impaired psychosocial functioning (mean GAF score $=60.9 \pm 8.9$ ).

Most PD subjects had a current history of Axis I disorder (75 of 100 ; mean $=1.3 \pm 1.0$ ) and nearly all had a life history of Axis I disorder (89 of 100 ; mean $=2.7 \pm 1.7$ ). Current Axis I disorders were as follows: Any Mood Disorder $(n=35)$ : Major Depression $(n=9)$, Dysthymia $(n=9)$, Depressive Disorder-NOS $(n=11)$; Any Anxiety Disorder $(n=13)$, ie, Phobic $(n=9)$, and Non-Phobic $(n=4)$ Anxiety Disorder; intermittent explosive disorder: IED by DSM-IV $(n=25)$, IED-R $(n=49)$, IED-IR $(n=59)$. Lifetime Axis I disorders were as follows: Any Mood Disorder $(n=62)$ : Major Depression $(n=33)$, Dysthymia $(n=10)$, Depressive Disorder-NOS $(n=28)$; Any Anxiety Disorder $(n=20)$, ie, Phobic $(n=14)$, and Non-Phobic $(n=9)$ Anxiety Disorder; Substance Use Disorders $(n=40)$ : Alcoholism $(n=34)$, Drug Dependence $(n=20)$; IED by DSM-IV $(n=26)$, IED-R $(n=48)$, IED-IR $(n=62)$.

\section{Assessment of Aggression, Impulsivity, and Suicidal Behavior}

Primary clinical and questionnaire measures of aggression included the Aggression scale of Life History of Aggression (LHA) and the Aggression scale of the BDHI (Buss and Durkee, 1957), respectively. The LHA assessment was completed by a research psychiatrist after a semi-structured interview with the subject, and consideration of other available clinical data, as in previous studies (Coccaro et al, 1996d). LHA aggression assesses the frequency of actual aggressive behavior over the lifetime. BDHI aggression assesses the tendency that someone acts aggressively. Primary assessments of impulsivity included the Barratt Impulsiveness Scale-Version 11 (BIS-11; Barratt, 1985) and the Impulsivity Scale from the Eysenck Personality Inventory (Eysenck and Eysenck, 1977). BIS-11 and EPQImpulsivity are both self-report assessments of impulsiveness. These assessments were included because of the relevance of impulsiveness in 5-HT-mediated aggression (Linnoila et al, 1983). Suicidal (and self-injurious) behavior was assessed in the context of the diagnostic assessments described above and was defined as in previous studies (Coccaro et al, 1989).

\section{General Preparation for Study}

Only 31 of the 150 subjects (all were personality disordered subjects) had any lifetime history of exposure to psychotropic agents. No subject was taking any psychotropic agent for at least 2 weeks at the time of study. Subjects were instructed to follow a low-monoamine diet for at least 3 days before study. Subjects were also informed that initial and follow-up urine toxicology would be performed randomly just before study; illicit drug use was not detected in any subject reported herein. Females were all studied within the first 10 days of the follicular phase of the menstrual cycle.

\section{d-Fenfluramine Challenge}

Subjects reported to the Clinical Procedures Lab at approximately 0800 hours after an overnight fast. An i.v. was inserted in a forearm vein and kept open by normal saline at a slow drip. Basal blood samples for PRL were collected in an EDTA tube at 0945 hours and at 0955 hours. d-FEN $(0.5 \mathrm{mg} / \mathrm{kg}$ body weight) was given orally at 1000 hours. Post-d-FEN blood samples for plasma PRL were collected in an EDTA tube every $30 \mathrm{~min}$ for up to $5 \mathrm{~h}$ (1500 hours). Samples for plasma levels of d-FEN and its metabolite, d-NorFEN, were collected in a potassium oxylate-coated tube at 1,3 , and $5 \mathrm{~h}$ after administration of d-FEN. All plasma samples were spun down immediately, separated, and then frozen at $-20{ }^{\circ} \mathrm{C}$ until assay. PRL samples were assayed by RIA; intra- and inter-assay CV were 10 and $12 \%$, repectively. Plasma levels of d-FEN and d-NorFEN were determined by gas chromatography with electrochemical detection (Krebs et al, 1984); intra- and inter-assay $\mathrm{CV}$ were $<7 \%$.

\section{Statistical Analysis}

The testing the statistical significance of differences between groups of subjects (eg, PD vs $\mathrm{HV}$ ) on categorical variables was carried out by $\chi^{2}$. Similar testing of dimensional variables was carried out by $t$-test or ANOVA/ANCOVA. Associations among variables were performed by Pearson correlation for two variables and by multiple regression for multiple variables. The primary outcome measure for the d-FEN challenge was the residual peak delta $(\Delta)$ PRL [d-FEN] response adjusted for relevant covariates. Residual peak $\triangle P R L[d-F E N]$ responses were obtained by regressing the raw peak $\triangle$ PRL[d-FEN] value (ie, (Peak $\triangle$ PRL[dFEN])-(averaged baseline PRL)) onto inter-subject variables including age, gender, body weight, baseline PRL, and peak total d-FEN (d-FEN + D-NorFEN) plasma levels. This was carried out to remove any confounding variance from raw peak $\triangle \mathrm{PRL}[\mathrm{d}-\mathrm{FEN}]$ values associated with these variables (Coccaro and Kavoussi 1994). Residual peak $\triangle \mathrm{PRL}[\mathrm{d}-\mathrm{FEN}]$ responses were highly correlated with residual placebo-corrected peak $\triangle \mathrm{PRL}[\mathrm{d}-\mathrm{FEN}]$ responses $(r=0.89, n=112, P<0.001)$ and were used in all analyses to maximize statistical power (since one-fourth of subjects did not undergo a placebo-challenge study). Residual peak $\triangle \mathrm{PRL}[\mathrm{d}-\mathrm{FEN}]$ responses were normally distributed across subjects and are hereafter referred to as $\triangle \mathrm{PRL}[\mathrm{d}-\mathrm{FEN}]-\mathrm{R}$ responses. $\triangle \mathrm{PRL}[\mathrm{d}-\mathrm{FEN}]-\mathrm{R}$ responses did not differ as a function of race $(\mathrm{F}[1,147]=0.99, p=0.371)$, socioeconomic status $(\mathrm{F}[1,145]=1.20, \quad p=0.313)$, season of study $(F[1,146]=0.37, p=0.772)$, or history of lifetime exposure to psychotropic agents $(\mathrm{F}[1,98]=0.13, p=0.72)$ in the PD subjects. Raw scores for LHA aggression and BDHI aggression were highly correlated with each other ( $r=0.77, n=133, p<0.001)$, as were the raw scores for BIS impulsivity and EPQ-II impulsivity $(r=0.80, n=115$, 
$p<0.001)$. Accordingly, raw LHA/BDHI aggression, and BIS/EPQ impulsivity, variables were converted to Z-Scores to create composite aggression and composite impulsivity variables, respectively. Correlations between $\triangle \mathrm{PRL}$ [d-FEN]-R responses and composite aggression were first examined in all subjects, then in all males and all females (examined separately) and finally, in all PD and all HV subejcts (examined separately). On the basis of previous data, our hypothesis was that $\triangle \mathrm{PRL}[\mathrm{d}-\mathrm{FEN}]-\mathrm{R}$ responses would correlate inversely with composite aggression in all subjects, all male subjects, and all PD subjects. The twotailed- $\alpha$ for these $a$ priori correlations were set at $p=0.05$. Next, correlations between $\triangle$ PRL[d-FEN]-R responses and composite impulsivity were examined in the same manner, testing a similar hypothesis, with a two-tailed- $\alpha$ of 0.05 . Finally, correlations between $\triangle \mathrm{PRL}[\mathrm{d}-\mathrm{FEN}]-\mathrm{R}$ responses and general personality measures from the Eysenck Personality Questionnaires were examined in the same manner, testing the hypothesis, that general personality measures would not correlate with $\Delta \mathrm{PRL}[\mathrm{d}-\mathrm{FEN}]-\mathrm{R}$ responses and, if they did, they would not do so after accounting for composite aggression and/or impulsivity scores. Group comparisons were first carried out among HV and PD subjects with and without a history of suicide attempt with an $\alpha$ of 0.05 . The a priori hypothesis tested was that $\triangle P R L[\mathrm{~d}-\mathrm{FEN}]-\mathrm{R}$ responses would be lowest among PD subjects with a history of suicide attempts, next lowest among PD subjects without a history of suicidal attempt, and highest among healthy controls. Differences in $\triangle$ PRL[d-FEN]-R responses between PD subjects without a history of suicide attempt and HV subjects would be accounted for by differences in composite aggression and/or composite impulsivity scores. Group comparisons among PD subjects meeting, or not meeting, the different criteria sets for IED were set at a two-tailed- $\alpha$ of 0.05 . The $a$ priori hypothesis was that the difference in $\triangle \mathrm{PRL}[\mathrm{d}-\mathrm{FEN}]-\mathrm{R}$ responses among IED and non-IED subjects would be greatest among PD subjects meeting IED by integrated research criteria.

\section{RESULTS}

Demographic, functional, and behavioral data for the PD and HV subjects are displayed in Table 1. Although the two groups did not differ in the distribution of gender, race, or in socioeconomic class, they did differ in functional (PD with lower GAF) and behavioral (PD with higher aggression and impulsivity) variables as expected. The difference in age between the groups was statistically significant but relatively small in magnitude.

\section{$\Delta$ PRL[d-FEN]-R Responses and Dimensional Measures of Aggression}

Correlations between the variables among all subjects revealed a significant, inverse, relationship between $\triangle \mathrm{PRL}[\mathrm{d}-\mathrm{FEN}]-\mathrm{R}$ responses and composite aggression $(r=-0.34, n=133, p<0.001)$; Figure 1. Correlations among subjects by gender were also inverse and statistically significant (males: $r=-0.34, n=90, p<0.001$; females: $r=-0.41, n=43, p=0.006$ ). Correlations among subjects by diagnostic group status were similar in direction but somewhat lower for PD subjects $(r=-0.28, n=88$, $p=0.011)$ and not statistically significant among $\mathrm{HV}$ subjects $(r=-0.17, n=45, p=0.273)$. Correlations among male and female PD subjects were similar but only reached statistical significance in male PD subjects (males: $r=-0.32, n=59, p=0.013$ vs females: $r=-0.24, n=29$, $p=0.213$ ), the difference in the correlations between male and female PD subjects was not significant.

\section{$\Delta$ PRL[d-FEN]-R Responses and Dimensional Measures of Impulsivity}

Correlations between the variables among all subjects also revealed a marginally statistically significant, inverse, and small relationship between $\triangle \mathrm{PRL}[\mathrm{d}-\mathrm{FEN}]-\mathrm{R}$ responses and composite impulsivity $(r=-0.19, n=115, p<0.05)$. Compared with composite aggression, which accounted for

Table I Demographic, Functional, and Behavioral Data: PD vs HC Subjects

\begin{tabular}{|c|c|c|c|c|}
\hline Variable & PD Subjects $(n=100)$ & HC Subjects $(n=50)$ & Statistic & $P$-value \\
\hline \multicolumn{5}{|l|}{ Demographic } \\
\hline Age & $35.0 \pm 8.9$ & $28.4 \pm 6.7$ & $t_{125.3}=5.07$ & $<0.001$ \\
\hline Gender (M/F) & $67 / 33$ & $36 / 14$ & Fishers exact test & 0.580 \\
\hline Race (white/non-white) & $76 / 24$ & $32 / 18$ & Fishers exact test & 0.129 \\
\hline $\operatorname{SES}(|/| I / I I / / V N)$ & $3 / 15 / 32 / 36 / 14$ & $0 / 10 / 20 / 14 / 6$ & $\chi^{2}=3.36, d f=4$ & 0.500 \\
\hline \multicolumn{5}{|l|}{ Functional } \\
\hline GAF & $56.1 \pm 10.6$ & $85.3 \pm 4.7$ & $t_{146.4}=23.27$ & $<0.001$ \\
\hline \multicolumn{5}{|l|}{ Behavioral } \\
\hline LHA aggression & $12.3 \pm 7.2$ & $3.8 \pm 4.3$ & $t_{139}=8.89$ & $<0.001$ \\
\hline
\end{tabular}




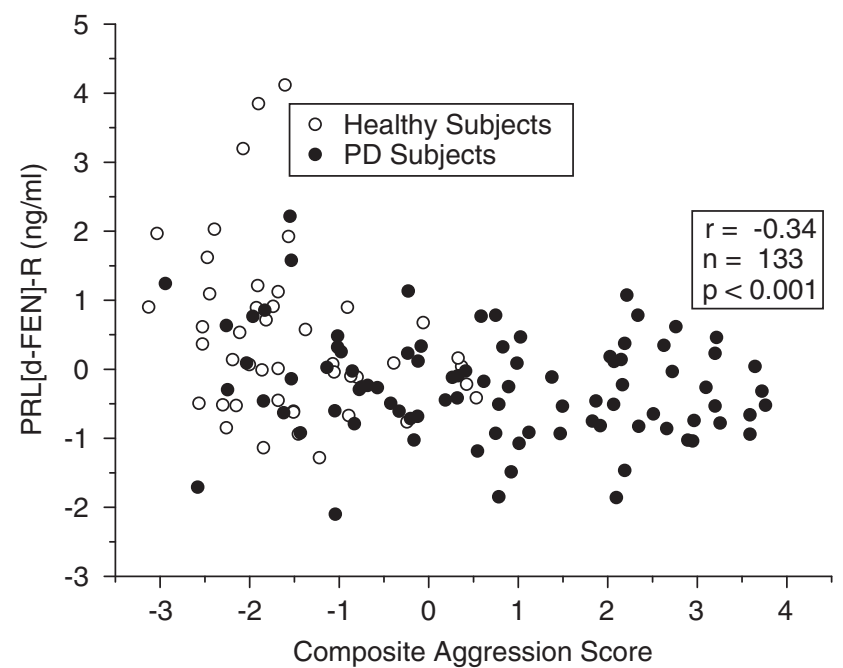

Figure I Correlation between PRL[d-FEN]-R and composite aggression values in all PD and all $\mathrm{HC}$ subjects. Correlation in all subjects: $r=-0.34$, $p<0.00$ I; correlation in all PD subjects: $r=-0.28, p=0.01 \mathrm{I}$; correlation in all $\mathrm{HC}$ subjects: $r=-0.17, p=0.273$.

$11.6 \%$ of the variance in $\triangle \mathrm{PRL}[\mathrm{d}-\mathrm{FEN}]-\mathrm{R}$ responses, composite impulsivity accounted for only $3.6 \%$ of the variance in these values. Notably, Composite impulsivity and composite aggression were strongly correlated $(r=0.66, n=107, p<0.001)$. Subsequent multiple regression analysis, adding both composite aggression and composite impulsivity into the same model, revealed that only composite aggression contributed unique variance to $\triangle \mathrm{PRL}[\mathrm{d}-\mathrm{FEN}]-\mathrm{R}$ responses (overall $\mathrm{F}[2,104]=7.93$, $p<0.001$; composite aggression: $\beta=-0.420$, partial $r=-0.32, \quad p<0.001$; composite impulsivity: $\beta=0.098$, partial $r=0.08, p=0.42$ ).

$\triangle P R L[d-F E N]-R$ Responses and Dimensional Measures of General Personality: Neuroticism, Psychoticism, and Extraversion

$\triangle \mathrm{PRL}[\mathrm{d}-\mathrm{FEN}]-\mathrm{R}$ responses correlated inversely and significantly, in all subjects, with EPQ Neuroticism $(r=-0.26$, $n=120, p=0.004)$ and EPQ Psychoticism $(r=-0.24, n=$ $120, p=0.008)$ but not EPQ Extraversion $(r=0.13, n=120$, $p=0.154)$. However, both personality dimensions correlated with composite aggression (Neuroticism: $r=0.69$; Psychoticism: $r=0.53 ; p<0.001$ for both), and multiple regression analysis entering composite aggression, neuroticism, and psychoticism revealed that only composite aggression uniquely explained any variance in $\triangle \mathrm{PRL}[\mathrm{d}$ FEN]-R responses $(\beta=-0.165, t=2.15, p<0.035)$.

\section{$\triangle$ PRL[d-FEN]-R Responses and History of Suicide Attempt}

Twenty-six of the 100 PD subjects (26\%) had a history of at least one suicide attempt $(\mathrm{SA}+)$; by definition, none of the healthy controls had this history. $\triangle \mathrm{PRL}[\mathrm{d}-\mathrm{FEN}]-\mathrm{R}$ responses were significantly lower among $\mathrm{SA}+$ subjects compared with $\mathrm{SA}-$ subjects and the $\triangle \mathrm{PRL}[\mathrm{d}-\mathrm{FEN}]-\mathrm{R}$ responses of these two SA/PD groups were both lower than

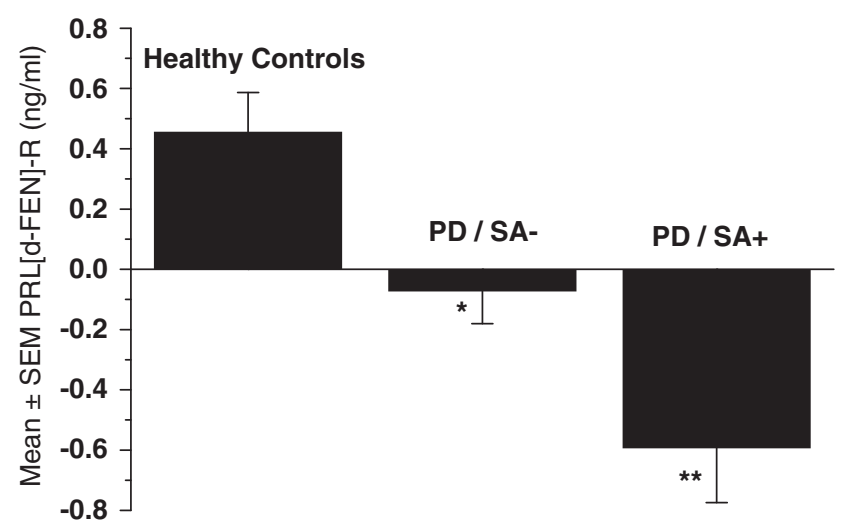

Figure 2 Mean ( \pm SEM) PRL[d-FEN]-R values in $\mathrm{HC}$ subjects (left) and in PD subjects without history of suicide attempt (middle; PD/SA-) and in PD subjects with history of suicide attempt (right; PD/SA +). $* 0<0.02$ for $\mathrm{PD} / \mathrm{SA}$ - vs HC, *** $p<0.05$ for PD/SA + vs PD/SA - and $p<0.00$ I for PD/ $\mathrm{SA}+$ vS HC.

that of the HV subjects $(\mathrm{F}[1,147]=6.10 . p=0.015)$; Figure 2 . Among the SA/PD subjects, however, composite aggression scores were significantly higher among the SA + subjects $\left(t_{86}=3.41, p=0.001\right)$. When these scores were included in an ANCOVA model, no statistically significant difference in $\triangle \mathrm{PRL}[\mathrm{d}-\mathrm{FEN}]-\mathrm{R}$ responses were observed between $\mathrm{SA}+$ and SA - subjects $(\mathrm{F}[1,97]=0.66, p=0.417$; effect size $=0.11 \mathrm{SD})$. Nineteen of the $100 \mathrm{PD}$ subjects $(19 \%)$ had a previous history of self-injurious behavior. In contrast to history of suicidal behavior, no difference was observed in $\triangle \mathrm{PRL}[\mathrm{d}-\mathrm{FEN}]-\mathrm{R}$ responses as a function of a history of self-injurious behavior $\left(t_{98}=0.26, p<0.80\right)$.

\section{Group Differences In $\Delta \mathrm{PRL}[\mathrm{d}-\mathrm{FEN}]-\mathrm{R}$ Responses Between HV and PD Subjects}

Consistent with the findings above, mean $\triangle \mathrm{PRL}[\mathrm{d}-\mathrm{FEN}]-\mathrm{R}$ responses were significantly lower $\left(t_{71.9}=3.37, p=0.001\right.$; effect size $=0.64 \mathrm{SD})$, and mean composite aggression scores were significantly higher $\left(t_{131}=9.80, p<0.001\right)$, in PD compared with HV subjects. When composite aggression scores were included in an ANCOVA model the magnitude of this difference, while remaining marginally statistically significant $(\mathrm{F}[1,130]=4.01, p<0.05)$, was reduced by about a third (effect size $=0.42 \mathrm{SD}$ ).

\section{$\triangle P R L[d-F E N]-R$ Responses and IED, Borderline PD and Antisocial PD}

Among PD subjects, those with DSM-IV IED demonstrated little difference in $\triangle P R L[\mathrm{~d}-\mathrm{FEN}]-\mathrm{R}$ responses those without DSM-IV IED (effect size $=0.10 \mathrm{SD} ; t_{98}=0.45, p<0.65$ ). However, the magnitude of this difference increased threefold when IED-R criteria was used (effect size $=$ $0.31 \mathrm{SD} ; t_{98}=1.54, p<0.13$ ) and was fourfold as high and statistically significant when IED-IR criteria were used (ie, met IED by either DSM-IV or IED-R criteria; effect size $\left.=0.41 \mathrm{SD} ; t_{98}=1.99, p<0.05\right)$. Subjects with IED-IR also had higher composite aggression scores (effect size $\left.=1.50 \mathrm{SD} ; t_{86}=10.98, p<0.001\right)$ than the remaining subjects. When these scores were added to an ANCOVA 
Table 2 Demographic, Functional, and Behavioral Data: IED-IR vs Non-IED-IR Subjects

\begin{tabular}{|c|c|c|c|c|}
\hline Variable & IED-IR Subjects $(n=62)$ & Non-IED-IR Subjects $(n=38)$ & Statistic & $P$-value \\
\hline \multicolumn{5}{|l|}{ Demographic } \\
\hline Age & $36.8 \pm 9.1$ & $32.1 \pm 7.9$ & $t_{98}=2.62$ & 0.010 \\
\hline Gender (M/F) & $45 / 17$ & $22 / 16$ & Fishers exact test & 0.188 \\
\hline Race (white/non-white) & $50 / 12$ & $26 / 12$ & Fishers exact test & 0.228 \\
\hline SES $(I / I / / I / / I V / N)$ & $2 / 9 / 19 / 26 / 6$ & $1 / 6 / 13 / 10 / 8$ & $\chi^{2}=3.92, \mathrm{df}=4$ & 0.417 \\
\hline \multicolumn{5}{|l|}{ Functional } \\
\hline GAF & $53.1 \pm 9.7$ & $60.9 \pm 10.4$ & $t_{98}=3.80$ & $<0.001$ \\
\hline \multicolumn{5}{|l|}{ Behavioral } \\
\hline LHA aggression & $16.2 \pm 5.6$ & $6.2 \pm 4.6$ & $t_{98}=9.04$ & $<0.001$ \\
\hline
\end{tabular}

model, the magnitude of the difference between the groups was reduced by more than half (effect size $=0.17 \mathrm{SD}$ ) and was statistically nonsignificant $(\mathrm{F}[1,85]=0.288 . p=0.59)$. Demographic, functional, and behavioral data for the IEDIR and non-IED-IR subjects are displayed in Table 2. Although the two groups did not differ in the distribution of gender, race, or in socioeconomic class, they did differ in functional (low GAF) and behavioral (high aggression and impulsivity) variables as expected. The difference in age between the groups was statistically significant but relatively small in magnitude.

Composite aggression scores were also higher in DSM-IV Borderline PD (effect size $=0.98 \mathrm{SD} ; t_{48.6}=5.19, p<0.001$ ) and in DSM-IV Antisocial PD subjects (effect size $=0.92 \mathrm{SD}$; $\left.t_{25.5}=4.55, p<0.001\right)$ compared with PD subjects without these diagnoses. However, differences in $\triangle \mathrm{PRL}[\mathrm{d}-\mathrm{FEN}]-\mathrm{R}$ responses were not statistically significant in either group (Borderline PD: effect size $=0.20 \mathrm{SD} ; t_{98}=0.87, p<0.39$; Antisocial PD: effect size $=0.15 \mathrm{SD} ; t_{98}=0.57, p<0.58$ ).

\section{$\Delta$ PRL[d-FEN]-R Responses and Axis I Variables}

$\triangle \mathrm{PRL}[\mathrm{d}-\mathrm{FEN}]-\mathrm{R}$ values did not differ as a function of current history of mood disorder $(\mathrm{F}[1,96]=0.90, p=0.346)$, phobic $(\mathrm{F}[1,96]=0.75, p=0.389)$ or non-phobic $(\mathrm{F}[1,96]=$ $1.18, p=0.281)$ anxiety disorder or as a function of a life history of mood disorder $(\mathrm{F}[1,95]=0.13, p=0.738)$, phobic $(\mathrm{F}[1,95]=1.38, p=0.244)$ or non-phobic $(\mathrm{F}[1,95]=1.19$, $p=0.278)$ anxiety disorder, or alcoholism/drug dependence $(\mathrm{F}[1,95]=1.31, p=0.256)$.

\section{DISCUSSION}

The results of this study confirm results of other studies displaying an inverse correlation between PRL responses to acute challenge with fenfluramine and psychometric measures of aggression (Coccaro and Siever, 2005). In this study, $\triangle \mathrm{PRL}[\mathrm{d}-\mathrm{FEN}]-\mathrm{R}$ responses were inversely correlated with a composite measure of aggression composed of a life history of aggression (LHA-A) assessment and a personality assessment of aggression proneness (BDHI) both of which were highly correlated, but not completely overlapping in variance (ie, shared variance $\sim 50 \%$ ). The absence of a similarly strong relationship with a composite measure of impulsivity (composed of BIS-11 and EPQ-2 impulsivity) was unexpected given data from some previous studies. Compared with composite impulsivity scores, composite aggression scores explained greater than three times the variance in $\triangle \mathrm{PRL}[\mathrm{d}-\mathrm{FEN}]-\mathrm{R}$ values composite impulsivity (11.8 vs 3.5\% of the variance). As, after accounting for the effect of composite aggression scores, composite impulsivity scores added nothing more to the relationship with $\triangle \mathrm{PRL}[\mathrm{d}-\mathrm{FEN}]-\mathrm{R}$ responses, it is apparent that the variance represented by composite impulsivity, and shared with composite aggression (shared variance $=44 \%$ ), is what is reflected by the part of composite aggression that correlates uniquely with $\triangle \mathrm{PRL}[\mathrm{d}-\mathrm{FEN}]-\mathrm{R}$ responses. Accordingly, it may be appropriate to say that impulsivity describes the type of aggression associated with reduced 5-HT function rather than say that reduced 5-HT function is simply associated with both generalized impulsivity and generalized aggression

It is notable that the inverse relationship between $\triangle \mathrm{PRL}[\mathrm{d}-\mathrm{FEN}]-\mathrm{R}$ responses and composite aggression was present in both males and females, examined separately regardless of diagnostic group. This suggests that the aggression/ $\triangle \mathrm{PRL}[\mathrm{d}-\mathrm{FEN}]-\mathrm{R}$ response relationship runs across gender $\left(r^{2}=0.11\right.$ for all males $v s 0.16$ all females) and is not statistically different in magnitude between the genders. Similar inverse relationships were seen in PD and HV subjects, although they were only statistically significant in the PD subjects. Examining degrees of shared variance between the groups, the magnitude of the correlation was nearly 2.7-fold greater in the PD group compared with that in the HV group ( $r^{2}=0.08$ for PD vs 0.03 for $\mathrm{HV}$ ), although not statistically significantly different than that of the PD group. Comparing this relationship in male and female PD 
subjects, the magnitude of the difference in the correlation between the genders $\left(r^{2}=0.10\right.$ for males $v s 0.06$ for females) was only about 1.7 -fold greater in males than in females and not statistically significant. This suggests that the inverse relationship between composite aggression and $\triangle \mathrm{PRL}[\mathrm{d}-$ FEN]-R responses is greatest in PD males but, also, likely present in PD females at a lower magnitude. Given that females made up only about $33 \%$ of the PD sample, it is possible that the nonsignificance of the relationship in females was due to lower statistical power to detect the relationship at $p=0.05 \alpha$-level.

An inverse correlation between $\Delta \mathrm{PRL}$ [d-FEN]-R response and general personality measures, such as EPQ Neuroticism and Psychoticism, is a new finding. However, although both EPQ scales correlated with $\triangle$ PRL[d-FEN]-R responses, both were highly correlated with composite aggression scores. After accounting for the relationship between the three variables only composite aggression scores made a unique contribution to $\triangle \mathrm{PRL}[\mathrm{d}-\mathrm{FEN}]-\mathrm{R}$ responses. This suggests that the relationship between aggression and PRL[d-FEN] responses is primarily to aggression and not to general measures of personality. This is strengthened by the observation that EPQ Extraversion displayed no relationship with $\triangle$ PRL[d-FEN]-R responses.

Lower $\triangle \mathrm{PRL}[\mathrm{d}-\mathrm{FEN}]-\mathrm{R}$ responses among $\mathrm{PD}$ subjects with a life history of suicide attempt is consistent to what has been reported in several other studies. Similar to our own previous studies, with d,l-FEN challenge, this relationship appeared to be related to the inverse correlation between composite aggression and $\triangle \mathrm{PRL}[\mathrm{d}-\mathrm{FEN}]-\mathrm{R}$ responses. Specifically, adding composite aggression scores to the model reduced the effect of history of suicide attempt on $\triangle \mathrm{PRL}[\mathrm{d}-\mathrm{FEN}]-\mathrm{R}$ responses to nonsignificance. On the other hand, it is possible that this may be be due to the greater variance in composite aggression variable, compared with that in the history of suicide attempt variable. The absence of an effect of history of self-injurious behavior on $\triangle \mathrm{PRL}$ [dFEN]-R responses is a new negative finding consistent with the hypothesis that regulation of self-injurious behavior is related more to non-5-HT neurotransmission.

Lower $\triangle \mathrm{PRL}[\mathrm{d}-\mathrm{FEN}]-\mathrm{R}$ responses among $\mathrm{PD}$, compared with $\mathrm{HV}$, subjects was expected given that the PD subjects had LHA-aggression scores threefold higher, and BDHIaggression scores twofold higher, than that observed in the HV subjects. This was also expected because we have previously reported that $\mathrm{PD}$ subjects are more aggressive than HV subjects (Berman et al, 1998). Adding composite aggression scores to the model, including diagnostic group and $\triangle \mathrm{PRL}[\mathrm{d}-\mathrm{FEN}]-\mathrm{R}$ responses, reduced the magnitude of the group difference by one-third and reduced the statistically significance of this difference from $p<0.001$ to $p<0.05$.

Given the inverse relationship between $\triangle \mathrm{PRL}[\mathrm{d}-\mathrm{FEN}]-\mathrm{R}$ responses and composite aggression, a critical question is if this relationship will also be reflected in lower PRL [d-FEN]-R values among diagnostic groups in which aggression is an important component. In this regard, the three most important diagnostic groups are IED, BPD, and Antisocial Personality Disorder (AsPD). In this study we found no significant difference in $\triangle$ PRL[d-FEN]-R responses as a function of BPD or AsPD. Given the relatively small numbers of these types of subjects $(n=16-28)$, however, it is noteworthy that the effect size of these differences were relatively small at $0.15 \mathrm{SD}$ (AsPD) to 0.20 SD (BPD).

With IED, group differences depended on the diagnostic criteria used. DSM-IV IED was not associated with a significant difference in $\triangle P R L[d-F E N]-R$ responses and demonstrated only a small effect size (0.10 SD). Using IED-R research criteria (which requires the presence of frequent, if not always severe, impulsive aggressive outbursts (eg, two per week on average for at least 1 month) tripled the size of the difference between groups (effect size $=0.31 \mathrm{SD}$ ), although this was still not statistically significant. Including PD subjects who met either DSM-IV or IED-R research criteria (ie, integrated research criteria: IED-IR), however, quadrupled the size of this difference (effect size $=0.41$ ) and was statistically significant. Close examination of these data (Figure 3) suggests that it is important to include both types of IED diagnoses (ie, in to an integrated diagnostic model: IED-IR), so that aggressive individuals are not incorrectly placed in the 'non-aggressive' category (artificially reducing mean PRL[d-FEN]-R responses in this group). This finding is similar to that reported previously by New et al (2004), using IED-R criteria in a large study of personality disordered subjects involved in a study using d,l-FEN as the 5-HT challenge probe. Accordingly, these data extend, and replicate, previously reported findings in demonstrating an inverse relationship between 5-HT and a clinically relevant form of aggression as expressed by the research diagnostic criteria sets for IED.

Intermittent explosive disorder is a disorder of aggression, typically impulsive in nature, not better accounted for by other psychiatric/medical conditions or by pharmacologically induced behavioral states. In recent epidemiologic studies, IED has a lifetime prevalence of about 3-7\% depending on the study and the specific diagnostic criteria used (Coccaro et al, 2004; Kessler et al, 2006). Although subjects who met IED by any of the three criteria sets, compared with corresponding non-IED subjects, demonstrated a reduction in $\triangle \mathrm{PRL}$ [d-FEN]-R responses, only the integrated IED research criteria (IED-IR) demonstrated a significant reduction in $\triangle \mathrm{PRL}$ [d-FEN]-R responses. It is notable that IED-IR criteria was associated with reduced $\triangle$ PRL[d-FEN]-R responses, compared with DSM-IV criteria, because IED-IR criteria allows for frequent, although low

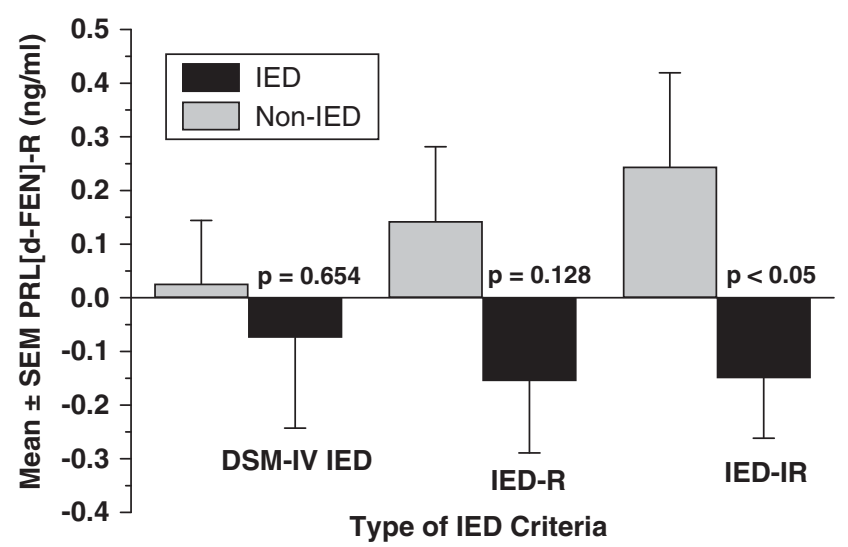

Figure 3 Mean $( \pm S E M) P R L[d-F E N]-R$ values in PD subjects with and without IED by DSM-IV criteria (left), by IED-R criteria (middle), and by IED-IR criteria (right) 
intensity, aggressive episodes. Such episodes are allowed in the diagnostic set only if they involve clinically significant verbal aggression and non-destructive aggression against objects (ie, episodes that are associated with subjective distress and/or impairment of occupational or psychosocial function).

The observation that inclusion of verbal and nonassaultive aggressive episodes, as a diagnostic criteria for IED, is associated with a reduction in $\triangle \mathrm{PRL}[\mathrm{d}-\mathrm{FEN}]-\mathrm{R}$ responses appears to support the validity of including these kinds of aggressive episodes in the next iteration of the diagnostic criteria for IED in DSM-V. Data from other studies also support the validity of IED-IR (and IED-R) criteria in regard to the inclusion of verbal and non-assaultive aggressive episodes. First, IED subjects with verbal aggression, alone, do not differ from other IED subjects in a validated behavioral aggression task (McCloskey et al, 2008a). Second, neuroimaging studies using IED-R criteria have reported, compared with controls, abnormalities in 5-HT activation in the frontal cortex (Siever et al, 1999) and in the anterior cingulate cortex (New et al, 2002) and have reported reduced numbers of neuronal 5-HTT-binding sites in the anterior cingulate cortex, and possibly other areas as well (Frankle et al, 2005). In addition, an fMRI study of emotional information processing in IED-IR subjects reported enhanced amygdala activation, compared with controls, specifically, in response to exposure to angry faces. Third, treatment with fluoxetine (Coccaro et al, 2009) or cognitive-behavioral treatment (McCloskey et al, 2008b) clearly reduces verbal/nonassaultive aggressive behavior in subjects with IED-IR.

The observation that only integrated IED research criteria (IED-IR) demonstrated a significant reduction in $\triangle \mathrm{PRL}[\mathrm{d}-$ FEN]-R responses is also notable because IED-IR, but not DSM-IV, criteria allow for the inclusion of impulsive aggressive subjects with comorbid BPD/AsPD. Although $\triangle \mathrm{PRL}[\mathrm{d}-\mathrm{FEN}]-\mathrm{R}$ responses in $\mathrm{BPD} / \mathrm{AsPD}$ subjects were not reduced to a statistically significant degree, these $\triangle \mathrm{PRL}[\mathrm{d}-$ FEN]-R responses were reduced only by a small-to-modest effect size. Assigning these subjects in the 'IED Negative' group (as does DSM-IV criteria), as opposed to assigning them to the 'IED Positive' group (as does IED-IR criteria), clearly reduces the power for IED subjects by DSM-IV criteria to demonstrate a reduction in central 5-HT function, as it should, if those criteria are to identify a group of impulsive aggressive individuals with a deficit in central 5-HT function.

These data extend those of other studies, as well, by using $\mathrm{d}-\mathrm{FEN}$ as the 5-HT challenge probe. Most studies have involved d,l-FEN, which contains equal quantities of its d- and 1- isomers. Animal studies suggest different properties and potencies, within serotonergic and dopaminergic systems with regard to these two isomers. Specifically, the $\mathrm{d}$-isomer is more potent at 5-HT release and uptake inhibition compared with the l-isomer (Invernizzi et al, 1986). In addition, the l-isomer has clear effects on the central dopaminergic system as evidenced by its ability to increase brain levels of homovanillic acid (HVA), a major metabolite of dopamine (DA) (Crunelli et al, 1980). Although the specific mechanism of l-FEN's effect on brain HVA is not clear, some investigators suggest that l-FEN exerts a 'neuroleptic-like' action on DA receptors (Garattini et al, 1988). Such an action would appear to compromise the ability of FEN to assess central 5-HT system function, particularly where the PRL response to FEN is used as the primary outcome variable. This is because DA exerts a powerful inhibitory influence on the pituitary lactotroph (Ben-Jonathan et al, 1989). Accordingly, PRL responses to d,l-FEN could be due to both the enhancement in 5-HT function and the inhibition of the tuberoinfundibular DA system, which directly regulates PRL secretion. At least one study in human subjects suggests that l-FEN (as part of the d,l-formulation) is associated with an inhibition of the tuberoinfundibular DA system. This study (Mitchell and Smythe, 1991) reported that $60 \mathrm{mg}$ of d,l-FEN was associated with a robust increase in plasma levels of HVA. This increase in plasma HVA was temporally correlated with the PRL response to d,l-FEN and was linearly correlated with the maximal PRL response to d,l-FEN challenge. These data were interpreted as evidence that the PRL response to d,l-FEN represented, at best, a mixed signal reflecting central 5-HT and tuberoinfundibular DA system function. Notably, we have shown that this effect on plasma HVA is not present when using d-FEN in human subjects (Coccaro et al, 1996b). Accordingly, the present findings should reflect the responsivity of the central 5-HT system, particularly in the limbic hypothalamus.

The pharmacology underlying PRL[d-FEN] responses is complex. d-FEN enters the 5-HT terminal through the 5-HT transporter and releases 5-HT from the 5-HT terminal where upon it is available to stimulate pre- and postsynaptic receptors. At the same time, d-FEN blocks the further uptake of synaptic 5-HT. The net effect of these actions is a large increase of 5-HT in the synaptic cleft. Various studies with agents that interfere with pre- and post-synaptic 5-HT function have been performed and have revealed much about the nature of the PRL[d-FEN] response. First, acute tryptophan depletion studies demonstrate a significant reduction in the PRL[d-FEN] response during tryptophan depletion (Coccaro et al, 1998b) and suggest that the PRL[d-FEN] response is largely reflecting 5-HT that has been newly synthesized (eg, that typically prepared for release on neuronal impulse). Second, PRL[dFEN] responses appear to reflect activation of 5-HT-2c, but not 5-HT-1a or 5-HT-3, receptors. PRL[d-FEN] responses can be completely abolished both in rats (Di Renzo et al, 1989) and humans (Goodall et al, 1993) by ritanserin, and in humans by the 5-HT-2a/2c antagonist, amesergide (Coccaro et $a l, 1996 \mathrm{c})$. Given the absence of effect of 5-HT-1a (pindolol; Park and Cowen, 1995), 5-HT-2a (amperozide; Albinsson et al, 1994), and 5-HT-3 (ondansetron; Coccaro et al, 1996a) antagonists on PRL[d-FEN] responses, it is likely that the PRL[d-FEN] responses are largely due to activation of 5-HT-2c post-synaptic receptors in the limbic hypothalamus with 5-HT that has been newly synthesized.

In summary, physiologic responses to central 5-HT stimulation with d-FEN are reduced as a function of aggression (but not generalized impulsivity) in human subjects. The same is true for PD subjects with a history of suicidal, but not self-injurious, behavior and for subjects with a diagnosis of IED by research criteria. On the basis of our knowledge of the neuropsychopharmacology of d-FEN, central 5-HT deficits in impulsive aggressive individuals are likely due to abnormalities involving 5-HT-2c post-synaptic 
receptors in the limbic hypothalamus (Coccaro et al, 1996c). These data also suggest that the word impulsive, in the term impulsive aggression, describes the form of aggression (ie, as impulsive in nature) associated with central 5-HT deficits demonstrated by a reduction in $\triangle \mathrm{PRL}$ [d-FEN]-R responses and not impulsivity in general. In addition, these data suggest that categorical definitions of impulsive aggression should include frequent, although low intensity, episodes of impulsive aggression (ie, verbal and non-destructive physical impulsive aggression) and include subjects with comorbid BPD/AsPD PDs if they also meet the remaining criteria for IED.

\section{ACKNOWLEDGEMENTS}

This study was funded in part by NIMH Grants RO1MH46948 and KO2MH00951 (Dr Coccaro). We thank Richard L Hauger, MD, Professor, Department of Psychiatry, UC San Diego School of Medicine, in whose laboratory the prolactin assays were conducted. We also thank Thomas B Cooper, MA, Professor, Department of Psychiatry, New York State Psychiatric Institute and the Nathan Kline Institute in Orangeburg, New York, in whose laboratory the d-Fenfluramine/d-Norfenfluramine assays were conducted.

\section{DISCLOSURE}

The authors declare that EFC is currently on the Scientific Advisory Board of Azivan Pharmaceuticals. In addition, the authors declare that EFC has received compensation from Pfizer Pharmaceuticals, as a consultant; CHDI Management, as a consultant; Worldwide Clinical Trials, as a consultant; and has received final payments on investigator-initiated research studies from Eli Lilly Laboratories and from Abbott Laboratories in the past 3 years. None of the products of these companies are associated with this work and neither of the two research studies declared being funded for any of the work reported in this paper. The authors declare that RJK is currently an employee in Research and Development at Glaxo Smith Kline and that RJK has held similar positions at Pfizer, and at Wyeth, in the past 3 years. RJK was not with any pharmaceutical, or other, company when this work was performed. Finally, the authors declare that RL has received no financial support or compensation from any individual or corporate entity over the past 3 years for research or professional service. In addition, RL has no personal financial holdings that could be perceived as constituting a potential conflict of interest.

\section{REFERENCES}

Albinsson A, Palazidou E, Stephenson J, Andersson G (1994). Involvement of the 5-HT2 receptor in the 5-HT receptormediated stimulation of prolactin release. Eur J Pharmacol 251: 157-161.

American Psychiatric Association (1994). Diagnostic and Statistical Manual of Mental Disorders 4th edn. American Psychiatric Association Press: Washington, DC.

Asberg M, Traskman L, Thoren P (1976). 5-HIAA in the cerebrospinal fluid. A biochemical suicide predictor? Arch Gen Psychiatry 33: 1193-1197.
Barratt E (1985). Impulsiveness defined within a systems model of personality. Erlbaum: Hillsdale, NJ.

Ben-Jonathan N, Arbogast LA, Hyde JF (1989). Neuroendocrine [corrected] regulation of prolactin release. Prog Neurobiol 33: 399-447.

Berman ME, Fallon AE, Coccaro EF (1998). The relationship between personality psychopathology and aggressive behavior in research volunteers. J Abnorm Psychol 107: 651-658.

Botchin MB, Kaplan JR, Manuck SB, Mann JJ (1993). Low versus high prolactin responders to fenfluramine challenge: Marker of behavioral differences in adult male cynmolgus macaques. Neuropsychopharmacology 9: 93-99.

Brown GL, Goodwin FK, Ballenger JC, Goyer PF, Major LF (1979). Aggression in humans correlates with cerebrospinal fluid amine metabolites. Psychiatry Res 1: 131-139.

Bunce SC, Noblett KL, McCloskey MS, Coccaro EF (2005). High prevalence of personality disorders among healthy volunteers for research: implications for control group bias. J Psychiatr Res 39: 421-430.

Buss AH, Durkee A (1957). An inventory for assessing different kinds of hostility. J Consult Psychol 21: 343-349.

Coccaro E, Siever L (2002). Pathophysiology and treatment of aggression. Psychopharmacology: the Fifth Generation of Progress $1709-1723$.

Coccaro EF (2003). Intermittent explosive disorder. In: Coccaro EF (ed). Aggression: Psychiatric Assessment and Treatment. Marcel Dekker Inc.: New York. pp 149-166.

Coccaro EF, Kavoussi RJ (1994). The neuropsychopharmacologic challenge in biological psychiatry. Clin Chem 40: 319-327.

Coccaro EF, Kavoussi RJ, Berman ME, Lish JD (1998a). Intermittent explosive disorder-revised: development, reliability, and validity of research criteria. Compr Psychiatry 39: $368-376$.

Coccaro EF, Kavoussi RJ, Cooper TB, Hauger R (1996a). 5-HT3 receptor antagonism by ondansetron does not attenuate prolactin response to d-fenfluramine challenge in healthy human subjects. Psychopharmacology (Berl) 127: 108-112.

Coccaro EF, Kavoussi RJ, Cooper TB, Hauger R (1998b). Acute tryptophan depletion attenuates the prolactin response to d-fenfluramine challenge in healthy human subjects. Psychopharmacology (Berl) 138: 9-15.

Coccaro EF, Kavoussi RJ, Cooper TB, Hauger RL (1996b). Hormonal responses to $\mathrm{d}$ - and d,l-fenfluramine in healthy human subjects. Neuropsychopharmacology 15: 595-607.

Coccaro EF, Kavoussi RJ, Cooper TB, Hauger RL (1997a). Central serotonin activity and aggression: inverse relationship with prolactin response to d-fenfluramine, but not CSF 5-HIAA concentration, in human subjects. Am J Psychiatry 154: $1430-1435$.

Coccaro EF, Kavoussi RJ, Oakes M, Cooper TB, Hauger R (1996c). 5 -HT2a/2c receptor blockade by amesergide fully attenuates prolactin response to d-fenfluramine challenge in physically healthy human subjects. Psychopharmacology (Berl) 126: 24-30. Coccaro EF, Kavoussi RJ, Sheline YI, Lish JD, Csernansky JG (1996d). Impulsive aggression in personality disorder correlates with tritiated paroxetine binding in the platelet. Arch Gen Psychiatry 53: 531-536.

Coccaro EF, Kavoussi RJ, Trestman RL, Gabriel SM, Cooper TB, Siever LJ (1997b). Serotonin function in human subjects: intercorrelations among central 5-HT indices and aggressiveness. Psychiatry Res 73: 1-14.

Coccaro EF, Lee RJ, Kavoussi RJ (2009). A double-blind, randomized, placebo-controlled trial of fluoxetine in patients with intermittent explosive disorder. J Clin Psychiatry 70: 653-662.

Coccaro EF, Schmidt CA, Samuels JF, Nestadt G (2004). Lifetime and 1-month prevalence rates of intermittent explosive disorder in a community sample. J Clin Psychiatry 65(6): 820-824. 
Coccaro EF, Siever LJ (2005). Neurobiology. In J. M. Oldham, A. E. Skodol \& D. Bender (Eds.). Textbook of Personality Disorders. American Psychiatric Press: Arlington, VA. pp 155-169.

Coccaro EF, Siever LJ, Klar HM, Maurer G, Cochrane K, Cooper TB et al (1989). Serotonergic studies in patients with affective and personality disorders. Correlates with suicidal and impulsive aggressive behavior. Arch Gen Psychiatry 46: 587-599.

Crunelli V, Bernasconi S, Samanin R (1980). Effects of d- and 1fenfluramine on striatal homovanillic acid concentrations in rats after pharmacological manipulation of brain serotonin. Pharmacol Res Commun 12: 215-223.

Di Renzo G, Amoroso S, Taglialatela M, Canzoniero L, Basile V, Fatatis A et al (1989). Pharmacological characterization of serotonin receptors involved in the control of prolactin secretion. Eur J Pharmacol 162: 371.

Eysenck SB, Eysenck HJ (1977). The place of impulsiveness in a dimensional system of personality description. $\mathrm{Br} J$ Soc Clin Psychol 16(1): 57-68.

Fishbein DH, Lozovsky D, Jaffe JH (1989). Impulsivity, aggression, and neuroendocrine responses to serotonergic stimulation in substance abusers. Biol Psychiatry 25: 1049-1066.

Frankle WG, Lombardo I, New AS, Goodman M, Talbot PS, Huang $Y$ et al (2005). Brain serotonin transporter distribution in subjects with impulsive aggressivity: a positron emission study with [11C]McN 5652. Am J Psychiatry 162(5): 915-923.

Garattini S, Bizzi A, Caccia S, Mennini T, Samanin R (1988). Progress in assessing the role of serotonin in the control of food intake. Clin Neuropharmacol 11(Suppl 1): S8-32.

Goodall EM, Cowen PJ, Franklin M, Silverstone T (1993). Ritanserin attenuates anorectic, endocrine and thermic responses to d-fenfluramine in human volunteers. Psychopharmacology (Berl) 112(4): 461-466.

Halperin JM, Sharma V, Siever LJ, Schwartz ST, Matier K, Wornell $\mathrm{G}$ et al (1994). Serotonergic function in aggressive and nonaggressive boys with attention deficit hyperactivity disorder. Am J Psychiatry 151(2): 243-248.

Higley JD, Mehlman PT, Taub DM, Higley SB, Suomi SJ, Vickers $\mathrm{JH}$ et al (1992). Cerebrospinal fluid monoamine and adrenal correlates of aggression in free-ranging rhesus monkeys. Arch Gen Psychiatry 49(6): 436-441.

Invernizzi R, Berettera C, Garattini S, Samanin R (1986). d- and l-isomers of fenfluramine differ markedly in their interaction with brain serotonin and catecholamines in the rat. Eur $J$ Pharmacol 120(1): 9-15.

Kessler RC, Coccaro EF, Fava M, Jaeger S, Jin R, Walters E (2006). The prevalence and correlates of DSM-IV intermittent explosive disorder in the National Comorbidity Survey Replication. Arch Gen Psychiatry 63(6): 669-678.

Krebs HA, Cheng LK, Wright GJ (1984). Determination of fenfluramine and norfenfluramine in plasma using a nitrogensensitive detector. J Chromatogr 310(2): 412-417.

Kruesi M, Rapoport J, Hamberger S, Hibbs E, Potter W, Lenane M et al (1990). Cerebrospinal fluid metabolites, aggression, and impulsivity in disruptive behavior disorders of children and adolescents. Arch Gen Psychiatry 47: 459-462.

Limson R, Goldman D, Roy A, Lamparski D, Ravitz B, Adinoff B et al (1991). Personality and cerebrospinal fluid monoamine metabolites in alcoholics and controls. Arch Gen Psychiatry 48(5): 437-441.

Linnoila $M$, Virkkunen $M$, Scheinin $M$, Nuutila A, Rimon $R$, Goodwin FK (1983). Low cerebrospinal fluid 5-hydroxyindoleacetic acid concentration differentiates impulsive from nonimpulsive violent behavior. Life Sci 33(26): 2609-2614.

Lopez-Ibor JJ, Lana F, Saiz Ruiz J (1990). Conductas autoliticas impulsivas y serotonina. Actas Luso-Esp Neurol Psiquiatr 18: 316-325.

Manuck SB, Flory JD, McCaffery JM, Matthews KA, Mann JJ, Muldoon MF (1998). Aggression, impulsivity, and central nervous system serotonergic responsivity in a nonpatient sample. Neuropsychopharmacology 19(4): 287-299.

McCloskey MS, Lee R, Berman ME, Noblett KL, Coccaro EF (2008a). The relationship between impulsive verbal aggression and intermittent explosive disorder. Aggress Behav 34(1): 51-60.

McCloskey MS, Noblett KL, Deffenbacher JL, Gollan JK, Coccaro EF (2008b). Cognitive-behavioral therapy for intermittent explosive disorder: a pilot randomized clinical trial. J Consult Clin Psychol 76(5): 876-886.

Mitchell PB, Smythe GA (1991). Endocrine and amine responses to D,L-fenfluramine in normal subjects. Psychiatry Res 39(2): 141-153.

New AS, Hazlett EA, Buchsbaum MS, Goodman M, Reynolds D, Mitropoulou V et al (2002). Blunted prefrontal cortical 18fluorodeoxyglucose positron emission tomography response to meta-chlorophenylpiperazine in impulsive aggression. Arch Gen Psychiatry 59(7): 621-629.

New AS, Trestman RL, Mitropoulou V, Benishay DS, Coccaro E, Silverman J et al (1997). Serotonergic function and self-injurious behavior in personality disorder patients. Psychiatry Res 69(1): 17-26.

New AS, Trestman RF, Mitropoulou V, Goodman M, Koenigsberg $\mathrm{HH}$, Silverman J et al (2004). Low prolactin response to fenfluramine in impulsive aggression. J Psychiatr Res 38: 223-230.

O'Keane V, Moloney E, O'Neill H, O'Connor A, Smith C, Dinan TG (1992). Blunted prolactin responses to d-fenfluramine in sociopathy. Evidence for subsensitivity of central serotonergic function. Br J Psychiatry 160: 643-646.

Park SB, Cowen PJ (1995). Effect of pindolol on the prolactin response to d-fenfluramine. Psychopharmacology (Berl) 118(4): 471-474.

Pine DS, Coplan JD, Wasserman GA, Miller LS, Fried JE, Davies M et al (1997). Neuroendocrine response to fenfluramine challenge in boys. Associations with aggressive behavior and adverse rearing. Arch Gen Psychiatry 54: 839-846.

Sheard MH, Marini JL, Bridges CI, Wagner E (1976). The effect of lithium on impulsive aggressive behavior in man. $A m \mathrm{~J}$ Psychiatry 133: 1409-1413.

Siever LJ, Buchsbaum MS, New AS, Spiegel-Cohen J, Wei T, Hazlett EA et al (1999). d,l-fenfluramine response in impulsive personality disorder assessed with [18F]fluorodeoxyglucose positron emission tomography. Neuropsychopharmacology 20: 413-423.

Stoff DM, Pastiempo AP, Yeung JH, Cooper TB, Bridger WH, Rabinovich H (1992). Neuroendocrine responses to challenge with $\mathrm{d}, \mathrm{l}$-fenfluramine and aggression in disruptive behavior disorders of children and adolescents. Psychiatry Res 43: $263-276$

Virkkunen M, Nuutila A, Goodwin FK, Linnoila M (1987). Cerebrospinal fluid monoamine metabolite levels in male arsonists. Arch Gen Psychiatry 44(3): 241-247.

Westergaard G, Suomi S, Higley J, Mehlman P (1999). CSF 5-HIAA and aggression in female macaque monkeys: Species and interindividual differences. Psychopharmacology 146: 440-444. 